\title{
Africa and China Higher Education Cooperation and Exchange: Effects of the Short-term Seminars
}

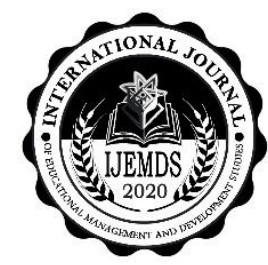

\author{
${ }^{1}$ Jean Gonondo \& ${ }^{2}$ Célestine Laure Djiraro Mangue
}

\begin{abstract}
This paper presents the cooperation and exchanges between African countries and China in the field of higher education, precisely the case of the short-term seminars organised by China for African scholars. It aims at looking more closely into the effects of these shortterm seminars. Based on online surveys, interviews, observations and personal experiences, the study found that these short-term seminars benefit both Africa and China by strengthening participants' skills, broadening international views on the one hand, and strengthening China's international relations ties on the other hand. Based from the results, some concrete suggestions to strengthen higher education cooperation and exchanges between African countries and China in general were formulated to improve the quality and efficiency of these short-term seminars in particular. These suggestions include the establishment of an exchange platform, the improvement of the quality of communication, the promotion of scholarship awarding for long-term studies to young Africans, and the promotion of mutual understanding.

Keywords:

Africa, China, higher education cooperation and exchange, effects of the short-term seminars

Suggested Citation: Gonondo, J. \& Djiraro Mangue, C.L. (2021). Africa and China Higher Education Cooperation and Exchange: Effects of the Short-term Seminars. International Journal of Educational Management and Development Studies, Volume 2, Issue 1, pp. 22 -42 .
\end{abstract}

About the authors:

${ }^{1}$ Corresponding author. Lecturer - Higher Teachers' Training College, University of Maroua, P.O. Box 55 Maroua (Cameroon)

${ }^{2}$ Lecturer, Higher Teachers' Training College, University of Maroua, P.O. Box 55 Maroua (Cameroon) 


\section{Introduction}

Since the 1950s, Africa and China have considered higher education as an essential part of their cooperation. Both sides attach great attention to higher education cooperation and exchange, especially since the establishment of the Forum on China and Africa Cooperation (FOCAC) in 2000. The launch of FOCAC at the early start of the new century gave a new trend of development to the cooperation and exchanges between African countries and China.

During the sixth FOCAC in December 2015 in Johannesburg, South Africa, President Xi Jinping declared: "We will work with our Africans friends to embrace a new era of mutually beneficial cooperation and common development" (Xi, 2017). During that meeting, he reminded that Chinese and Africans should strengthen partnership by observing some pillars, which are: commitment to political equality and mutual trust, mutually beneficial economic cooperation, mutually enriching cultural exchange, solidarity, and coordination in international affairs, and mutual assistance in security. To address three bottleneck issues including inadequate infrastructure, lack of professional and skilled personnel, and a shortage of capital, which are holding back Africa's development, he declared that China would implement ten cooperation programs with Africa. These programs include industrialisation, agricultural modernisation, infrastructure, finance, green development, trade and investment facilitation, poverty reduction, public health, peace, and security, cultural and people-topeople exchange program (Xi, 2017). Education is one of the cultural and people-to-people exchange programs.

Education, in general, is one of the essential cooperation fields between China and African countries. Both sides attach particular attention to higher education cooperation. African and Chinese people see in higher education cooperation and exchange not only the key for mutual understanding, acceptance, and support but also the key for sustainable development. Higher education cooperation and exchanges between African countries and China includes many programs. For example, the mobility of students, mobility of scholars and staff, exchange visits, the establishment of the Confucius Institutes in African countries' higher education institutions (HEIs), the creation of African studies institutes, African studies centers in the Chinese HEIs, the creation of Chinese studies institutes, Chinese studies 
centers in the African countries HEIs, the joint academic, research projects, and the shortterm seminars.

This study mainly focuses on the programs concerning short-term seminars in the area of higher education, precisely those organised by China, as in the case of Z University, for African countries. These programs are usually financed by the Chinese Government under the Ministry of Commerce and the Ministry of Education. The study aims to analyse the effects of the short-term seminars, which refer to the seminars held in China at $\mathrm{Z}$ University for about three weeks of duration.

\section{Literature review}

Contemporary China's foreign aid development can be divided into three essential stages: the first stage is from the 1950s to 1978, the second stage is from 1978 to 2002, and the third stage started from 2002 until now. In 1950, China opened the curtain on foreign aid by providing material aid to both North Korea and Vietnam. With the development of its international relations, China started not only to assist the socialist countries but also extended the aid to other developing countries. Based on the eight foreign aid principles, in 1964 the Chinese government has put forward four new tenets and announced the basic policy of its foreign aid, namely the principle of equality, mutual benefit, and free economic and technical assistance. Thus, in 1983, China held its first technical training program for developing countries in the capital, Beijing, to train professional and technical personnel. In 1998, the Chinese government held the first training program for officials, which was the seminar for economic management for African officials (Guowuyuan [国务院], 2011, 2014). From 1998 to the end of 2012, the Ministry of Commerce (MOFCOM) has held 334 training programs for a total of 8,846 officials from 153 countries and regions ( $\mathrm{Li}, 2015)$. In 2013, the Academy for International Business Officials (AIBO), MOFCOM carried out or allocated 522 training programs for about 13,500 participants (Reilly, 2015). Moreover, only in the year 2014 from January to October $29^{\text {th }}$, the same Ministry has held 443 training programs for officials $(\mathrm{Li}, 2015)$.

During the first period of China's foreign aid, some training programs were organised for human resources and technical personnel from developing countries. Some Chinese 
experts were sometimes sent to the recipient countries for special training. However, this phase of Chinese assistance concerned mainly the material and financial aid.

The main features of the second phase of Chinese assistance include the diversity of training forms, such as the training of technical personnel, the training of government officials and management personnel, the military trainees. Another feature is the increased number of trained staff year after year. From hundreds of professional and technical personnel in the 1983 China's foreign aid training, it has grown to thousands of trainees every year by 2002. In the beginning, the trainees were from Asian countries. However, from the second period of China's foreign aid, trainees were from more than 150 Asian, African and Latin American countries and regions. At this stage, China actively participated in the multilateral aid. For example, China has provided bilateral assistance to nine international organisations and 99 developing countries in cooperation with the United Nations development agencies and has trained 1500 technical talents (An Yang, 2013). During the second phase, the forms and fields of training were multiple, the contents were more specialised, the scope was wider and the effects were more noticeable.

The expansion of the training scale, the diversification of the programs, and the increase in the number of trainees characterised the third phase of China's foreign aid training. According to the statistics of the Ministry of Commerce, the Chinese government held 172 aid-training programs with 4,355 participants in 2002, of which the African participants reached nearly $40 \%$. Meanwhile, in 2006 a total of 260 programs were held, and about 6,000 trainees were received, of which $66.7 \%$ of the participants were Africans (An Yang, 2013).

Since the $21^{\text {st }}$ century, the Chinese government has also developed short-term training programs to train talent in various areas. These programs cover a wide range of courses for teachers and managers from universities, secondary and primary schools, managers of the Ministry of Commerce and technical personnel. There were also training courses on environmental protection, agriculture, medical and health.

The figure displays a short description of the whole process of the short-term seminars in China hosted by the Z University. 
Figure 1

The short-term seminars process in China hosted by the Z University

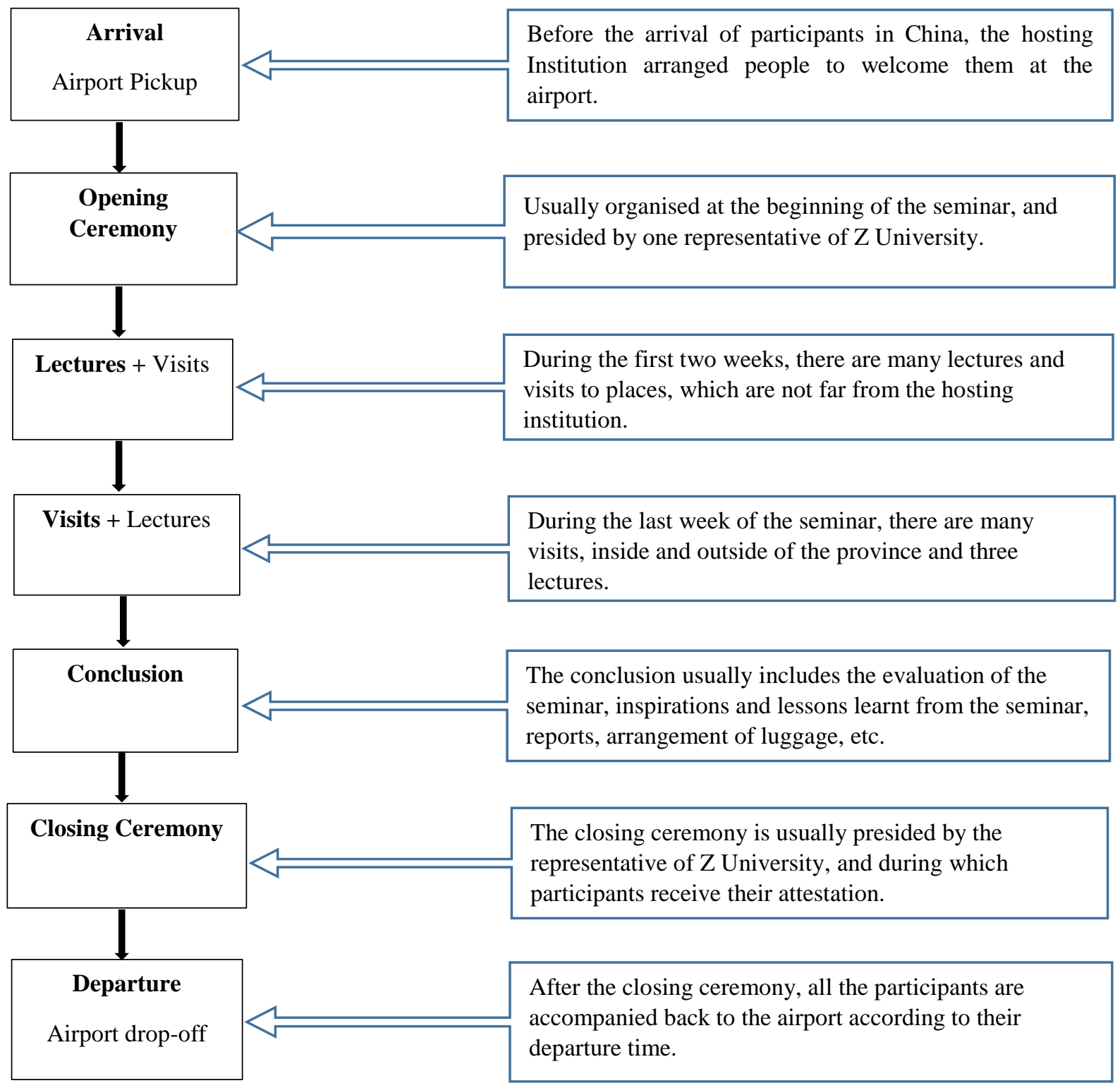

The foreign aid base of the Z University is among the ten China's Education Aid Base. For this purpose, this Institution held short-term seminars every year since 2002. This is known as one of the China's earliest foreign aid bases officially established by the government in 2004 after the first base established in Tianjin Vocational and Technical Teacher's College (currently the Tianjin University of Technology and Education) in 2003. 
The Ministry of Education, the Ministry of Commerce, and the Ministry of Foreign Affairs have assigned this base the mission of offering short-term seminars and training programs. From its establishment until February 2018, it has organised 131 short-term seminars and welcomed about 3200 persons from more than 80 countries and regions. It offers seminar and training programs in various fields, think-tank, pre-school education, basic education, higher education, technical and vocational education, sports education, art education, media, women empowerment, commerce, and politics, among others. Among the various groups of seminars hosted by Z University from 2002 to February 2018, this study identified 65 groups (49.61\%) that are related to higher education wherein $87.69 \%$ of the seminar participants were from African countries.

\section{Methodology}

\subsection{Research design}

This study used a mixed of quantitative and qualitative methods. The data gathering techniques are the online surveys, the observations, and the personal experiences of the researchers. Additionally, an in-depth interview was conducted to validate a more accurate, reliable, and trustworthy data and information.

The use of the online survey was encouraged because of the trend in many researches that use the same. Hayslett and Wildemuth (2004) and Martz (1999) as quoted by Wiersma and Jurs (2010) noted that the online survey answer rate is usually not so high compared to the on-the-spot paper survey questionnaire. Since the respondents are from the different African countries, the field survey requires considerable financial resources, more time, and more energy. Thus, it appears necessary to use an online survey for this study. Besides the online survey, an in-depth interviews with some Africans who participated in the short-term seminars at Z University were conducted.

\subsection{Participants of the Study}

The study purposively selected participants to the short-term seminars in the field of higher education organised by the Z University from May 18, 2010 to April 25, 2017. During this period, more than 600 Africans participated in the higher education short-term seminars 
at $\mathrm{Z}$ University. This group included the university presidents, vice presidents, deans, lecturers, researchers, scholars, and managers. They were from 19 African French-speaking countries and 18 African English-speaking countries. Since some African countries are bilingual, participants from these countries participated in both English and French seminars. Thus, the total respondents were taken from the 33 African countries. There were 38 different groups of short-term seminars identified from May 18, 2010 to April 25, 2017.

Based from the suggestion of Verma and Mallik (1999) to ensure a high response rate, a personalised cover letter according to the time and topic of the seminar they attended was sent to the participants. The cover letter is a short notice which explains the aim of the research, the importance of their participation in the study, and the assurance of confidentiality (Cohen et al., 2007).

\subsection{Survey Instrument}

Creswell (2013) notes that a "survey design provides a quantitative or numeric description of the trends, attitudes, or opinions of a population by studying a sample of that population". To assess the opinions of the former participants to the short-term seminars, the study used an online survey, preferred for objectivity, reliability, rapidity, cheapness, and ease of the data collection. The data were progressively collected through the internet after being mailed to the respondents.

Using the software wèn juàn xīng (问卷星) custom template, the new questionnaire content was created and sent to the participants for their completion. The questionnaire has six parts with a total of 32 items. The first part is a concise description of the questionnaire including the greeting, presentation of the aim of the study, and the importance of respondents' participation. The second part is about the basic information of respondents including the nationality, gender, age, and position. The third part elaborated on the afterseminar setups to know whether participants were in contact with either the Chinese or Africans after they returned home and the duration they have been in contact. It further dwelled on the specific occurrences such as who contacted whom, why and how they were contacted, and how long they have been in contact. The fourth part tackles the evidence of concrete output the participant prepared after the seminar. This includes the measures and actions like submitting a report to their hierarchies, re-echoing the seminar to their 
colleagues, and writing and publishing books, academic papers, reports, or news about the seminar. The fifth part is mainly concerned with the effectiveness of the seminar. It assessed the importance of the seminar to their work, effect on their perception of China and the Chinese people, appreciation and understanding of the Chinese culture and the Chinese educational system, and the promotion to a higher position after the seminar. The last part of the questionnaire deals with future implications that include the HEI cooperation with Chinese HEIs, possibility of joint research program with Chinese scholars, opportunity of attending similar seminar in China, and their suggestions to help realize the benefits of the seminar. The questionnaire was in English and French versions to accommodate the bilingual nature of the participants. The questionnaire was verified through a content validity check. It was checked and evaluated by the different experts in the field.

Upon the submission of the questionnaire response, the software program generates the results and sends the complete answers back to the researcher as graphed information or descriptive statistics. Within four weeks after the first mail-out as suggested by Salant and Dillman (1994), the online survey administration process was concluded. The results were generated from the software program for further analysis. The results were treated through the use of descriptive statistics such as frequency and percentage.

\subsection{Interview Process}

The face-to-face interviews with selected participants were conducted to gather supplemental information to the survey. The interview questions were formulated along with some themes such as the participants' expectations about the seminar, the general evaluation of the seminar, the impression about China, and suggestions for the improvement of the seminar. For confidentiality and ethical considerations, the identities of the participants were not disclosed. Each participant was coded with an alphabetic letter and number. There were 18 participants coded as E1, E2, E3, E4, E5, E6, E7, E8, F1, F2, F3, F4, F5, F6, F7, F8, F9, and F10. The letters $\mathrm{E}$ and $\mathrm{F}$ pertain to the English-speaking and French-speaking participants, respectively. The gathered data were categorized and organized according to themes. 


\section{Findings and Discussion}

Each seminar has an opening and a closing ceremony. The authors, themselves, have participated in these ceremonies and collected the representatives' speeches. During one of the closing ceremonies, the representatives of the host institution said:

"The time of the seminar was short, but our friendship remains perpetual. We strongly hope that you will keep in touch and strengthen cooperation with us when you get back home. We also warmly welcome outstanding students from your countries to study at our University".

It is perceptible that the Chinese leaders wish to keep in touch with the participants even after the short-term seminar. Accordingly, the chapter five, section ten of the revised edition of the Foreign Aid Training Project Implementation Management Handbook published in 2012 state that it is required for the institution-in-charge to keep in contact with the participants even after the seminar in China (AIBO, 2012). Additionally, the representative of $Z$ University on September $12^{\text {th }}, 2017$ during the closing ceremony of a seminar quote:

"We sincerely hope that after returning to your country, we will continue to strengthen, bring closer exchanges and cooperation to promote the development of China-Africa higher education".

The foregoing results present the contact between the participating countries.

\subsection{Contact}

\section{Table 1}

Percentage of African participants who contacted Chinese delegates after the seminar

\begin{tabular}{llll}
\hline Contacted persons & $\mathbf{\%}$ & Channels & $\mathbf{\%}$ \\
\hline Administrators of the seminar & 23.66 & Email & 36.1 \\
Interpreters & 10.05 & Phone call & 2.95 \\
Lecturers & 1.77 & Social network & 3.55 \\
Others & 4.14 & Others & 1.77 \\
\hline
\end{tabular}


Table 1 shows the percentage distribution of the African participants who contacted the Chinese delegates and the channels of their communication. Most of them contacted more than one participant. For instance, some of them contacted the administrators and the interpreters through email and social networks.

One of the crucial element of this study is to establish the after-seminar connection of the participants with Chinese experts, lecturers, interpreters, and managers. The results further show that $36.68 \%$ of the respondents answered that they had contacted the Chinese people after the seminar. Most of them made contact for greetings followed by asking or providing some information. Of the $36.68 \%$ respondents, $29.58 \%$ of them made contacts less than three times.

\section{Table 2}

Percentage of African participants who were contacted by Chinese delegates after the seminar

\begin{tabular}{llll}
\hline Contacted persons & $\mathbf{\%}$ & Channels & $\mathbf{\%}$ \\
\hline Administrators of the seminar & 36.09 & Email & 53.84 \\
Interpreters & 14.20 & Phone call & 2.36 \\
Lecturers & 1.18 & Social network & 1.77 \\
Others & 7.10 & Others & 1.18 \\
\hline
\end{tabular}

On the part of the Chinese organizers, $55.62 \%$ of the respondents have been contacted by them after the seminar. In contrast to the Africans, the Chinese delegates contacted the participants to provide them with some information. This communication from the Chinese delegates continued for some time. Among the 55.62\% respondents, $45.56 \%$ expressed that they have been contacted less than three times.

The results show that for many years after the seminar held in Z University, only few African scholars-participants had the initiative to contact the Chinese delegates, the Chinese 
has more frequently contacted them. While the African participants use to contact the Chinese for greetings, the Chinese organizers use to contact them to ask or transmit some information. Both of them mostly used email to keep in touch after the seminar.

\subsection{Outcomes of the seminar}

Majority of the African participants came to the China for the first time. The short period of exchange with Chinese lecturers and experts gave them knowledge and understanding about China. Many of them had a good impression on China and the Chinese people. After returning to their respective countries, participants have taken some measures to promote mutual understanding between Africans and Chinese. Majority of them shared with their colleagues, students, family, and friends about their seminar in China. Few of them have written and published books, scientific articles, and reports related to the cooperation between African countries and China. Some participants even expressed that their perceptions about China and the Chinese people have completely changed after the seminar.

The foregoing results were the participants' evaluation of the effects of the short-term seminars they had attended at the Z University.

\subsubsection{Initiatives resulting from the seminar}

Based from the analysis of the survey and the interview results, the foregoing are the summarised initiatives taken by the participants after the seminar.

\section{a. Report submission}

African scholars are used to presenting a report to their leaders. In this study, $95.85 \%$ of the participants said that they have submitted a report to their hierarchy. The outline of their report is summarised as follows: the introductory part which includes the framework and the purpose of the seminar; the next part is the semianar details that include content, duration, place, and the participants; the next part is a reflection on the most important and new content learned during the seminar and the suggestions for implementation; and lastly the prospection and summary. 


\section{b. Sharing and seminar re-echo}

The $78.10 \%$ of the participants shared the seminar contents with their colleagues, and $52.66 \%$ presented the seminar to their students. Among those of the latter, majority encouraged their students to continue their studies in China if they have the opportunity.

\subsubsection{Benefits of the seminar}

It was positively affirmed that the short-term seminars for African HEI managers and scholars are beneficial to both the Africans and the Chinese. During the interview, one of the university representative and lecturer said that China wishes to promote common development through fair cooperation (Gonondo, 2018). The summary of the benefits generated from the short-term seminars as narrated by the participants follows:

\section{a. Strenghten cooperation}

One of the mutual benefits African and Chinese participants get is the opportunity to write and publish books, articles, reports, and news to promote the relationship between China and the African countries. The results show that $6.51 \%$ of the participants were able to accomplish any of these.

\section{b. Mutual understanding}

The study also assessed whether participants gained knowledge and cultural understanding through the short-term seminars. The results were affirmative as answered by the $96.44 \%$ of the respondents that they have deepened their knowledge and understanding of the Chinese culture. During the seminar at Z University, it was observed that there were lectures in the field of higher education and Chinese culture. Participants also visited historical and cultural sites, museums and tourist spots. These type of activities allowed participants to directly assimilate more information and actual knowledge of the Chinese culture and society.

During the solemn closing ceremony, delegates use to give speech. The following part of a Chinese delegate speech was quoted during closing ceremony of September 12, 2017 at Z University.

"During these three weeks, through listening lectures, exchanging with 
Chinese scholars, visiting some places, etc., you have gotten a comprehensive understanding of China's politics, economy, and culture. During our exchanges with you, African friends, we have also learned about your culture. We know that China and African countries have great potential and a large space for cooperation in many fields. This information and knowledge will become our precious wealth and will also play a positive role in promoting our exchanges and cooperation in the future."

It was clearly mentioned that the Chinese organisers also learned about the African culture. The cultural exchange was very evident during the seminar.

The foregoing discussions are related to the benefits generated by the African HEIs from the short-term seminars attended by their delegations.

\section{c. Skills learned}

During the three-week seminar, the participants had about thirteen conferences including the Chinese language and culture and China higher education, and the field visits to Chinese HEIs, enterprises, historical and tourist places which are related to the seminar's topic. The Chinese lecturers and experts do not limit on the theoretical knowledge but also share practical knowledge and skills.

\section{Figure 2}

Respondents' Perception on the Applicability of Seminar Content to solve concrete problems

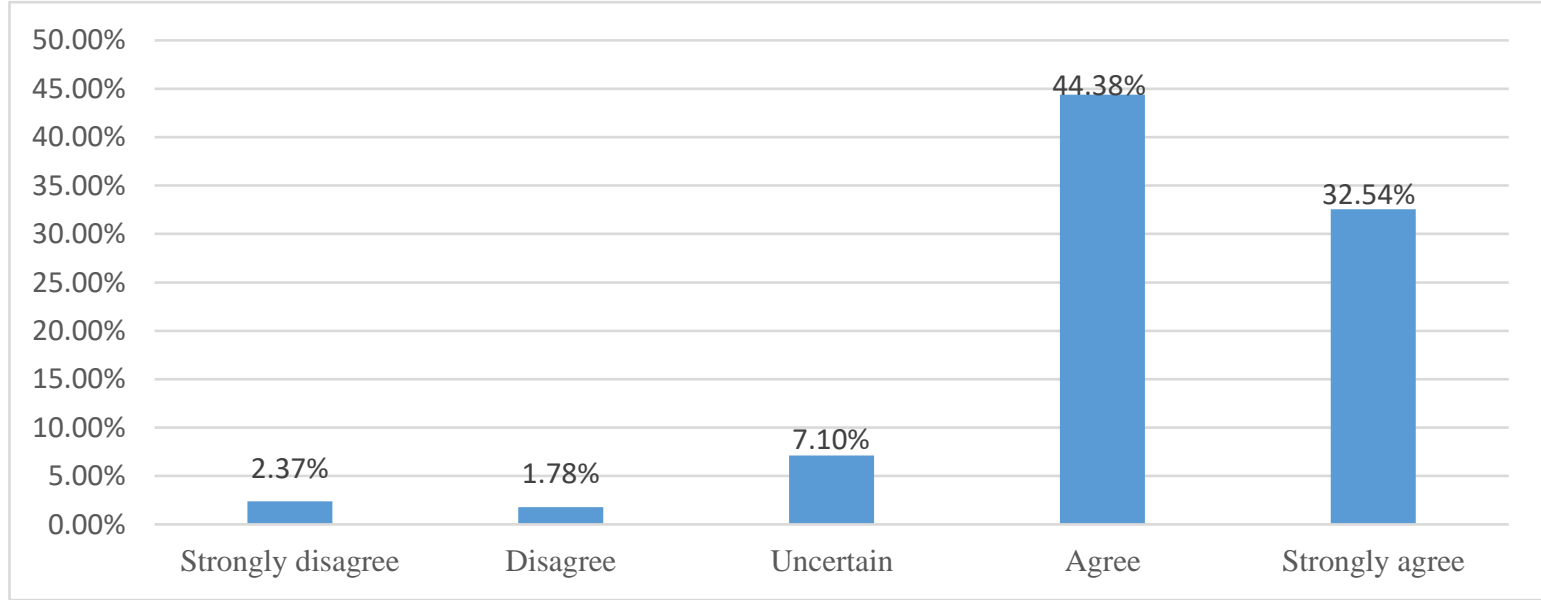


Majority of the participants affirmed that the seminar content is applicable and useful to solve some concrete problems at their workplace. As shown in Figure 2, $44.38 \%$ of the respondents agreed while $32.54 \%$ strongly agreed that the seminar contents are helpful to solve concrete problems at their workplaces.

Aside from the knowledge and skills to solve some concrete problems at work, majority of the respondents discovered the Chinese people as 'hard workers' and 'punctual', which inspired them to be the same.

\section{d. Establish camaraderie}

The seminars organised by the Z University in the field of higher education usually gathered participants not only from the different regions and countries but also from the different fields of higher education. For the participants, these seminars are not only an opportunity to understand more about China, its culture, educational system, and development, but also a good platform to meet people from other countries, regions, and fields. It was a platform to establish a friendly and long-term relationship with other lecturers, professors, experts from the different fields and countries. Respondent F4 said:

"During the short-term seminar entitled 'Seminar on Higher Education Management for African Countries', I have established a good relationship with Professors and Rectors from other African countries".

This kind of relationship and exchange with the African higher education scholars is very important and indispensable for the strengthening, development, and emergence of a powerful higher education in Africa.

\section{e. Knowledge deepening}

Respondent Participant F4 further elaborated:

"I participated three times in such seminar at $Z$ University in China. The topics of the lectures helped me to understand China better, and I appreciated the hospitality of Chinese people, their rich cultural and educational system”. 
Respondent F5 added that:

"The think-tank seminar I attended in 2012 has broadened my vision. Thanks a lot to the Chinese Government".

Participants also got entrepreneurial ideas after the seminar. Respondent F9 quipped:

"Thanks to the Think-tank seminar I attended at Z University, two other colleagues and I established a Pan-African Institute of Economic and Financial Management."

Another remarkable opportunity after the seminar for Africans working HEIs is the chance to come back to China to pursue their studies. There are young participants who chose to continue their studies in China after attending the seminar. For instance, Respondent F1 from Cameroon who is working at the University of Yaoundé said that he got the opportunity to participate in the short-term seminar in 2013 at that Z University. Later on, he had the chance to continue his studies in China. He cherished the opportunity, and since September 2015, he was enrolled in the field of Public Administration Management. He plans to go back to Cameroon to contribute to the development of his University.

"I am very grateful to the Chinese government for providing such a good opportunity. I am also grateful to my University's leaders who allowed me to cherish this opportunity to pursue my studies in China. After my graduation, I will return home to bring my knowhow for the development of my institution".

Other respondents such as E2 from Malawi, E3 from South Sudan and E4 from South Africa got the chance not only to participate in the short-term seminar but also to pursue their studies in China. They are now studying Comparative Education at the Institute of International Comparative Education at Z University.

The 28-year old Malawian, E2 respondent said:

"In the beginning, when I participated in the seminar concerning 'Art Education' in May 2016, it fascinated me. I was more excited 
when I discovered that this University also offers 'Comparative Education' programs. This major attracted me because I can learn what other countries are doing so that back home we can improve and develop our skills in this field. Now I'm interested in the inservice teachers' training. In certain regions where it is difficult to find another teacher from the same field, the teacher is abandoned to himself; there is no way to discuss professional experiences. This kind of short-term seminars is a very helpful platform to upgrade and improve teachers' knowledge and skills. Moreover, as a teacher, the training that we underwent during our training period should be continually done all through our professional life."

Other participants to the seminar had been given the chance to complete an undergraduate degree program at the Z University.

\section{f. Professional promotion}

The $31.91 \%$ of the surveyed participants confirmed that they had been promoted to a higher position after their attendance in the seminar. The different promotions include lecturer to a top administrative position and department positions to a university or ministry positions. Respondent E4 testified:

"Thanks to my participation in the seminar held in Z University, I have been promoted as Deputy Director of Planning, Administration, and Finance in my University."

Meanwhile, respondent F7 quipped:

"After the seminar, I have been promoted from Deputy Director to Director of my division."

The foregoing discussions are related to the benefits generated by the Chinas as the host country to the short-term seminars.

\section{g. International relations}


After the seminar, majority of the African participants organised an assembly where they presented the seminar details to their colleagues, students, family members, and friends. They also shared the visits to megalopolis like Beijing, Shanghai, Hangzhou, Qingdao, Sanya, Changchun, and Yiwu among others. Respondents said that aside that their memorable days in China were documented with pictures and videos taken during their stay.

There are various forms of reports prepared by the participants be it individually or collectively. For example, the Malian Education administrators prepared a group report and organised a meeting to share what they learned, and experienced. There were hundreds of people from the Chinese Embassy in Mali, Confucius Institute, Government Officials, HEI lecturers, and students who participated in this meeting. Through this assembly, the other Malians who were not attendees to the seminar get to experience and learn the same contents. They were also encouraged to participate in the seminar as well as to study in China. This process further strengthens the participation and international relations between the countries.

\section{h. Identity and image}

The other crucial aim of the study was to assess the perception of the participants about the host country before and after the seminar. The statistics show that $97.63 \%$ of the participants expressed a positive perception. They also affirmed that their perception of China and the Chinese people has positively changed. For instance, respondent F3 narrated:

\section{"Before coming to China, what I knew was that everywhere in China there was pollution, many people and no space, no liberty, bad quality of products. When I arrived here, I discovered that there are a lot of positive aspects of China that are not shown or rarely shown to us in Africa."}

With the newfound confidence on China and its people, $96.45 \%$ of the African scholars surveyed wanted a linkage and collaboration between their HEIs and the Chinese HEIs. Among the surveyed participants, $90.53 \%$ expressed their willingness to conduct a joint research project with the Chinese scholars. For instance, respondent E6 said:

"We would like to have more cooperation with Chinese HEIs for postgraduate studies, undergraduate studies, specialised training 
program, staff and students exchange, research projects, Chinese language teaching, and learning."

\subsubsection{Drawbacks and Suggestions for Improvements}

The respondents also identified some drawbacks on the seminar and suggested actions and strategies for the betterment of the program. The summary of the respondents' assessments of the drawbacks and their suggested strategies are listed herein.

\section{a. Exchange platform}

Although the Chinese government has encouraged institutions in charge of organising short-term seminars to provide follow-up service after the seminars, it has not been so easy due to the absence of a special unit or structure in charge of the follow-up. This is similar to the case of the $\mathrm{Z}$ University where no committees are formed for that purpose. In reality, the follow-up committee can give more updates and information about the participants, seminar theme and other pertinent information to establish good camaraderie and network. This can also get feedback from the participants in order to evaluate the quality and the effects of the seminar. In this era, information and communication technologies are more developed. Accordingly, there are platforms, which can be used for this purpose such as WeChat, WhatsApp, QQ, or any social networks group.

As the results primarily show that, the main purpose of the participants' follow-up is for greetings, respondents suggested an expansion of the follow-up to more concrete, helpful, and beneficial aspects. The contact between former participants and participants from the organising institution should emphasise sharing of knowledge, skills, expertise, and experiences (Gonondo, 2017).

\section{b. Quality of interpretation during the seminar}

The respondents mentioned about the presence of language barrier. These are common to countries using English as the Second Language. As such, respondent E3 particularly commented:

"The seminar was well organised, effective and beyond my expectations, however, the limitation has been the language 
barrier. The lectures and the visits created a positive impact on my previous knowledge about China and Chinese society. Before this visit, I was ignorant about the current Chinese reality."

Similarly, respondents E5, E7, E8, F7, F8, and F10 also suggested on the improvements of the language interpretation during the seminar.

\title{
c. Opportunity for young African participants
}

The results showed that young Africans who participated in the short-term seminars got the opportunity to come back to China to continue their studies. However, only few people got the opportunity as well as support from their respective institutions. There should be more young Africans to be sent to China to continue with their education. They can develop programs to allow them to continue their work and studies at the same time.

\section{d. Promotion of mutual understanding}

The short-term seminars should be considered as a platform for the promotion of mutual understanding. In this perspective, participant E4 suggested:

\begin{abstract}
"It is necessary to allow participants to present the higher education system of their respective countries to their Chinese friends. During the seminar, the African participants learn from the Chinese and other African colleagues. We would like also to share our history, our culture, and our best practices with our Chinese friends; mutual and real exchanges will make the seminar more meaningful."
\end{abstract}

\section{Conclusion}

This study assessed the short-term seminars in the area of higher education organised by the Z University in China for the African countries. These programs are held for three weeks which focus on the continuing professional development of the participants as well as cultural exchange. Through the survey and interview methods, the data gathered were treated and analysed using frequency and percentage for the quantitative data and thematic analysis for the qualitative data. 
Based from the results of the study, there is no doubt that both Africa and China benefit from the short-term seminars. The African participants benefit from the Chinese bestpractices while the host country, China, is strengthening and improving its international relations and image. The relations between African countries and China which started a long time ago could be strengthened if they continue to support and create a credible environment of cooperation. In the education sector, the African higher education and the Chinese scholars can increase their collaboration and mutual support. This is possible through research projects, short-term seminars, long-term studies, and creation of African and Chinese research centres.

This study is limited to the self-assessment of the participants on their personal experience and benefits gained from the short-term seminars. Although the study can be replicated in similar programs held in different countries, the nature of the programs and the involvement of the participants differ. An in-depth further studies on the benefits of the program to the workplace are highly encourage. In its simplest form, this study provides feedback on the organising university as well as the participants on the drawbacks and benefits of the short-term seminars.

\section{References}

AIBO. (2012). Shangwubu duiwai yuanzhu peixun xiangmu shishi guanli gongzuo shouce (2010 nian 8yue xiuding ban) [Ministry of Commerce Foreign Aid Training Project Implementation Management Handbook (Revised version August 2010)]. Academy for International Business Officials (AIBO), MOFCOM. http://www.chinaaibo.cn/article/content/view?id=318

An Yang. (2013). zhongguo yuanwai peixun lishi ji qianxi“中国援外培训历史及问题浅析” [History and problems of China's foreign aid training]. China Foreign Affairs University.

Cohen, L., Manion, L., \& Morrison, K. (2007). Research Methods in Education (6th ed.). Routledge Taylor \& Francis Group.

Creswell, J. W. (2013). Research Design: Qualitative, Quantitative, and Mixed Methods Approaches. In SAGE Publications (4th ed.). https://doi.org/10.1007/s13398-0140173-7.2

Gonondo, J. (2017). Africa and China Higher Education Cooperation: Establishing Knowledge Sharing Partnership between Students. Journal of Education and Practice, 8(10), 17-28. https://doi.org/http://dx.doi.org/10.7176/IJEP/2017/234

Gonondo, J. (2018). Africa and China Relation: The Basis of a Genuine Cooperation : An Interview with Prof . Dr. Lou Shizhou on a Possible Veritable Cooperation Between 
Africa and China. International Journal of African and Asian Studies, 42, 1-3. https://doi.org/http://dx.doi.org/10.7176/JAAS/42-7

Guowuyuan [国务院]. (2011). zhongguo de duiwai yuanzhu“中国的对外援助”[China's Foreign Aid]. 中华人民共和国国务院新闻办公室 [News Office of State Council, PRC]. http://www.gov.cn/zwgk/2011-04/21/content_1850553.htm

Guowuyuan [国务院]. (2014). zhongguo de duiwai yuanzhu“中国的对外援助 ”(2014)[China's Foreign Aid]. 中华人民共和国新闻办公室[News Office of State Council, PRC]. http://www.gov.cn/xinwen/2014-07/10/content_2715302.htm

Li, Q. (2015). zhongguo yuanwai peixun yanjiu: yi guoji guanyuan yanxiuban wei li" 中国援 外培训研究一以国际官员研修班为例”'CChina's Foreign Aid Training:From the Perspectives of International Officials Seminars]. Beijing Foreign Studies University.

Reilly, J. (2015). The role of China as an education aid donor.

Wiersma, W., \& Jurs, S. G. (2010). Research Methods in Education: An Introduction (9th ed.). Education Science Press.

$\mathrm{Xi}$, J. (2013). Xi Jinping zai tansangniya nileier guoji huiyi zhongxin de yanjiang (quanwen)[Speech by Xi Jinping at the Nyerere International Conference Center in Tanzania (full text)]. The Central People's Government of the People Republic of China. http://www.gov.cn/ldhd/2013-03/25/content_2362201.htm

Xi, J. (2014). Xi Jinping The Governance of China. Foreign Languages Press.

Xi, J. (2017). Xi Jinping The Governance of China II. Foreign Languages Press. 